\title{
EFEITO DA GEOMETRIA DOS DENTES DA SERRA DE FITA NA PRODUÇÃO DE MADEIRA SERRADA DE EUCALIPTO ${ }^{1}$
}

Graziela Baptista Vidaurre ${ }^{2}$, Benedito Rocha Vital ${ }^{3}$, José de Castro Silva ${ }^{3}$, José Tarcísio da Silva Oliveira ${ }^{4}$, Ana Márcia Macêdo Ladeira Carvalho ${ }^{3}$, Ricardo Marius Della Lucia ${ }^{3}$ e Angélica de Cássia Oliveira Carneiro $^{3}$

\begin{abstract}
RESUMO - O objetivo deste trabalho foi determinar o efeito dos parâmetros que compõem os dentes de serra de fita na produção e qualidade da madeira serrada de eucalipto. Analisou-se o efeito de dois passos de dentes (57,15 mm e passo variado: $50,8-50,8-50,39-50,71-60,03-60,35 \mathrm{~mm})$, de dois ângulos de ataque $\left(26\right.$ e $\left.27^{\circ}\right)$ e de duas alturas ( 22 e $25,4 \mathrm{~mm}$ ) em duas classes diamétricas ( 25 a $34 \mathrm{~cm}$ e 35 e $47 \mathrm{~cm}$ ) de clones de híbridos Eucalyptus grandis x Eucalyptus urophylla com 15 anos de idade. Não houve ganho de qualidade quando se trabalhou com passo variado. As lâminas de serra que possuíam ângulo de ataque de $27^{0} \mathrm{e}$ passo único tanto com altura do dente de $22 \mathrm{~mm}$ quanto com 25,4 mm geraram desvios acima da espessura-meta. A menor variação em torno da espessura-meta foi obtida quando se utilizaram lâminas de serra de ângulo de ataque de $27^{\circ}$ e altura do dente de $25,4 \mathrm{~mm}$. O maior desvio ocorreu quando o desdobro foi efetuado com passo variado e ângulo de ataque de $26^{\circ}$. A utilização de passo variado, de modo geral, foi o que apresentou maiores desvios na espessura das tábuas em relação à espessura desejada.
\end{abstract}

Palavras-chave: Eucalipto, serra fita e tábuas.

\section{EFFECT OF BAND SAW GEOMETRY ON THE PRODUCTION OF EUCALYPTUS SAWED WOOD}

\begin{abstract}
The objective of this work was to determine the effect of band saw teeth parameters on the production and quality of eucalyptus sawed wood. The effect of two tooth pitches $(57.15 \mathrm{~mm}$ and variable pitch: $50.8-50.8-50.39-50.71-60.03-60.35 \mathrm{~mm})$, two hook angles $\left(26\right.$ and $\left.27^{\circ}\right)$ and two gullet depths (22 and $25.4 \mathrm{~mm}$ ) on eucalyptus sawed wood was evaluated. Ten 15-year-old logs of Eucalyptus grandis $\mathrm{x}$ Eucalyptus urophylla clones were used. Logs were classified in two diameter classes with five logs displaying diameter between 25 to $34 \mathrm{~cm}$ and other five logs with diameter between 35 and $47 \mathrm{~cm}$. Variable pitches did not improve wood quality. Band saw with hook angle equal to $27^{\circ}$ and gullet depth of $22 \mathrm{~mm}$ or 25.4 mm provided positive cut deviation. The smallest thickness variation was found for band saw with gullet depth equal $25.4 \mathrm{~mm}$ and hook angle equal to $27^{\circ}$. The largest cut deviation was observed with variable pitch and hook angle of $26^{\circ}$.
\end{abstract}

Keywords: Eucalyptus, band saw and boards.

\footnotetext{
${ }^{1}$ Recebido em 11.03.2007 e aceito para publicação em 22.08.2008.

${ }^{2}$ Programa de Pós-Graduação em Ciência Florestal da Universidade Federal de Viçosa (UFV). E-mail:<grazibaptista@ yahoo.com.br>.

${ }_{3}^{3}$ Departamento de Engenharia Florestal da Universidade Federal de Viçosa (UFV). E-mail:<bvital@ ufv.br $>$.

${ }^{4}$ Departamento de Engenharia Rural da Universidade Federal do Espírito Santo (UFES). E-mail: <jtsilva@npd.ufes.br>.
} 


\section{INTRODUÇÃO}

A qualidade e rendimento de uma serraria dependem, entre outros fatores, da eficiência da serra empregada no desdobro das toras (BROWN, 1982; SANDVIK, 1999; STELLE et al., s.d.). Redução na espessura da lâmina de serra e, principalmente, aumento na precisão de corte, são metas importantes a serem consideradas quando se pretende aumentar a produção por metro cúbico de toras desdobradas (BROWN, 1982), além de melhorar a qualidade da madeira serrada. É necessário, ainda, selecionar o perfil do dente de serra mais adequado para a madeira a ser processada (LUNSTRUN, 1993). Embora qualquer tipo de dente consiga cortar qualquer tipo de madeira, a eficiência depende da seleção do perfil de dente mais apropriado para determinado tipo de corte e espécie de madeira a ser desdobrada (LUNSTRUN, 1993).

Densidade, umidade e orientação das fibras são as principais características das madeiras que afetam as forças de corte. Essas forças variam ainda em função da geometria da ferramenta de corte e das condições de usinagem (NÉRI et al., 2000). De modo geral, a geometria ideal é aquela que proporciona melhor qualidade e produtividade na madeira serrada. Segundo Pipino (2001), a geometria adequada dos dentes de serra reduz os esforços de corte, permitindo aumento da velocidade de avanço do carro porta-toras, proporcionando ganho de produtividade e redução no consumo de energia. Atualmente, técnicas modernas de afiação permitem variar, com alguma facilidade, ângulos, altura e passo dos dentes. Permitem ainda a afiação automática de lâminas com passo variado que, segundo Sandvik (1999) e Armstrong (2005), reduzem a vibração harmônica e as conseqüentes ondulações na madeira. Contudo, de modo geral, no Brasil diversos perfis de dentes são utilizados para o desdobro de madeira, independentemente da espécie. Costuma-se variar apenas a altura do dente e, em poucos casos, o ângulo de ataque ${ }^{5}$.

Atualmente, a maioria das espécies cultivadas em plantações florestais em áreas tropicais e subtropicais do mundo pertence ao gênero Eucalyptus (ALVES et al., 2004). Apesar disso, experimentações sobre desdobro de madeira desse gênero, principalmente no Brasil e relacionadas com perfis de dentes de serra, são restritas.
Extrapolações de resultados obtidos em outros países nem sempre são úteis, uma vez que as características das madeiras cultivadas no Brasil podem ser diferentes daquelas cultivadas em outros países. Além disso, dentro de uma mesma espécie podem ocorrer variações nas propriedades da madeira que interferem na usinagem (SILVA et al., 2005). No entanto, tem-se observado que a madeira serrada de eucalipto produzida com técnicas eficientes de desdobro e programas adequados de secagem gera produtos de alto valor comercial, aproximando-se de valores pagos a essências nativas de alto valor no mercado.

Uma das dificuldades na produção de madeira serrada de eucalipto está na manutenção das dimensões, principalmente a espessura final da peça serrada. Isso pode ser decorrente das elevadas tensões de crescimento e instabilidade dimensional encontradas no tronco de algumas espécies serradas no Brasil. Contudo, a variação dimensional das peças serradas, que pode ser afetada também pela geometria dos dentes de serra (ELEOTÉRIO et al., 1996), sendo as serrarias que processam madeiras com maior variação dimensional da espessura as que obtêm menores rendimentos. Por isso é necessário um acompanhamento permanente da produção, de forma a assegurar adequado controle dimensional. A medição da espessura, em ambos os lados, da peça serrada ao longo do seu comprimento é uma prática eficiente do controle de qualidade da madeira gerada pelo desdobro. Recomenda-se que esse processo seja executado por amostragem e concomitantemente ao processo de desdobro, principalmente depois da troca da lâmina de serra (UDDEHOLM, s.d.). Esse autor afirmou que a variação observada nas amostras deve representar o que pode ocorrer no processo produtivo e recomenda que a medição da espessura deve ser realizada em quatro pontos, distribuídos ao longo do comprimento e da largura das tábuas. Sugere ainda que, para se obter controle adequado, é necessário retirar 25 amostras ao longo do dia. Cada amostra deve conter quatro 4 tábuas distribuídas durante os turnos de funcionamento da serraria e, também, após a troca das serras. Ressalta, ainda, que cada amostra, constituída de quatro tábuas, deve ser retirada na mesma ocasião. O intervalo de amostragem deve ser de aproximadamente $4 \mathrm{~h}$. Carmo (2004), entretanto, estudando dois modelos de perfis de dente em serras de fita no desdobro de madeira

\footnotetext{
${ }^{5}$ Conforme terminologia empregada por Silva (2002) e Pipino (2001).
}

R. Árvore, Viçosa-MG, v.32, n.5, p.939-947, 2008 
nativa da Amazônia, empregou o mesmo critério de amostragem, porém mediu oito pontos, sendo quatro pontos de cada lado das tábuas, distribuídos apenas ao longo do comprimento.

O principal objetivo deste trabalho foi determinar o efeito de alguns parâmetros que compõem os dentes de serra de fita na produtividade e variações na espessura da madeira serrada de eucalipto. Como objetivo específico, analisou-se o efeito do passo dos dentes, ângulo de ataque e altura do dente na madeira serrada de eucalipto.

\section{MATERIAL E MÉTODOS}

As toras do híbrido Eucalyptus grandis $x$ Eucalyptus urophylla, com 15 anos de idade, utilizadas neste experimento foram colhidas em plantios comerciais da empresa Aracruz Produtos de Madeira (APM). Os plantios estavam localizados no Município de Mucuri, BA, a uma altitude de $82 \mathrm{~m}$, com latitude de 180 02'19' S e longitude de $39^{\circ} 51^{\prime} 43^{\prime \prime} \mathrm{W}$.

O delineamento experimental foi inteiramente casualizado, e os tratamentos consistiram em seis diferentes geometrias de dentes de lâminas de serra de fita, conforme pode ser observado no Quadro 1, e duas classes de diâmetro de toras de eucalipto. As toras foram processadas em um engenho de serra de fita com 1,82 $\mathrm{m}$ de diâmetro e velocidade de avanço definida pelo operador. Inicialmente, foram removidas quatro costaneiras, e, posteriormente, de cada bloco central foram serradas seis tábuas, mas após a remoção de cada tábua o bloco era girado em $90^{\circ}$. Foram desdobradas 10 toras por tratamento, sendo cinco para a classe diamétrica, compreendida entre $25-34 \mathrm{~cm}$ (classe 1), e as outras cinco toras com diâmetro entre 35 - 47 $\mathrm{cm}$ (classe 2).

Quadro 1 - Parâmetros dos dentes de serra de fita Table 1 - Band saw teeth parameters
O efeito das seis geometrias de dentes no processamento mecânico foi avaliado, determinandose a da velocidade de avanço e variação na espessura madeira serrada. Essas variáveis foram empregadas para determinar a produtividade do processamento e a espessura da madeira serrada.

Para a medição da espessura, as tábuas foram posicionadas em dois suportes de ferro devidamente confeccionados para facilitar a leitura das espessuras. Cada suporte permitia a leitura de cinco tábuas (Figura 1). As tábuas foram posicionadas de forma vertical para facilitar a medição da espessura nas duas laterais. Adotandose a metodologia empregada por Carmo (2004), os pontos de medição foram numerados em seqüência crescente, eqüidistantes, a partir da extremidade no qual o desdobro foi iniciado e marcados com giz de cera. Em cada tábua, foram tomadas 10 medidas de espessura, com o auxílio de um paquímetro digital, sendo cinco em cada lateral. Os cálculos dos desvios de corte foram baseados na metodologia proposta por Uddeholm (s.d.).

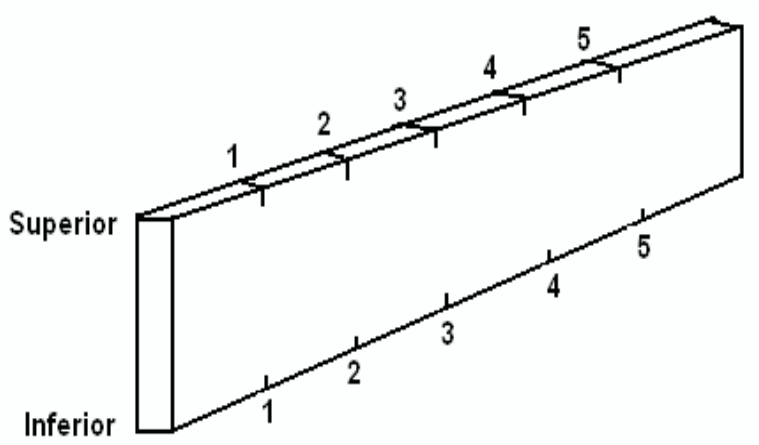

Figura 1 - Pontos de medição da espessura das tábuas ao longo do seu comprimento.

Figure 1 - Thickness measuring points of the boards along their length.

\begin{tabular}{|c|c|c|c|c|c|}
\hline \multirow[t]{2}{*}{$\overline{\text { Tratamentos }}$} & \multirow{2}{*}{$\begin{array}{l}\text { Passo } \\
(\mathrm{mm})\end{array}$} & \multirow{2}{*}{$\begin{array}{c}\text { Altura do } \\
\text { dente }(\mathrm{mm})\end{array}$} & \multicolumn{3}{|c|}{ Ângulo (graus) } \\
\hline & & & Incidência (ou livre) & Corte (ou cunha) & Ataque (ou gancho) \\
\hline 1 & 57,15 & 22 & 8 & 55 & 27 \\
\hline 2 & 57,15 & 22 & 9 & 55 & 26 \\
\hline 3 & 57,15 & 25,4 & 8 & 55 & 27 \\
\hline 4 & 57,15 & 25,4 & 9 & 55 & 26 \\
\hline 5 & variado $^{1}$ & 22 & 8 & 55 & 27 \\
\hline 6 & variado & 22 & 9 & 55 & 26 \\
\hline
\end{tabular}

${ }^{1} \mathrm{O}$ passo do dente variou na seguinte seqüência: 50,8 - 50,8 - 50,39-50,71-60,03-60,35 mm. 
Calculou-se a média da espessura, correspondente aos dois lados de cada tábua, gerando, portanto, cinco dados de espessura média de cada tábua e, em seguida, para cada tratamento. O desvio de corte absoluto, em porcentagem, foi calculado a partir dos desvios absolutos das espessuras médias de corte.

O tempo de corte de cada tábua foi obtido, empregandose um cronômetro digital, que foi acionado no momento emque a serra de fita tocava a tora e se paralisavaimediatamente quando o corte era finalizado. Conhecendo o comprimento das toras, a velocidade de avanço pôde ser calculada. Para cada tora foi obtida uma velocidade de avanço média, determinada a partir da velocidade de avanço de cada tábua de eucalipto desdobrada.

\section{RESULTADOS E DISCUSSÃO}

\subsection{Avaliação da espessura das tábuas}

No Quadro 2, bem como nas Figuras 2 e 3, apresentase a média geral dos desvios da espessura desejada das tábuas, em mm, bem como o desvio relativo, em porcentagem, em função dos tratamentos. Observase que os desvios que ocorreram nos seis tratamentos foram significativamente diferentes entre si, em nível de $95 \%$ de probabilidade. O menor e o maior desvio ocorreram nos tratamentos 2 e 6 , respectivamente. Considerando o desvio relativo em porcentagem, observou-se que apenas o tratamento 6 (passo variado e ângulo de ataque de $26^{\circ}$ ) foi significativamente diferente dos demais. A média de espessura obtida nas tábuas desdobradas com lâminas de serra com o passo variado e $26^{0}$ de ângulo de ataque distanciou $3,90 \%$ da espessura desejada de corte de $31,5 \mathrm{~mm}$.

Quadro 2-Desvio médio na espessura das tábuas por tratamento, desvio-padrão e desvio relativo na espessura, em porcentagem

Table 2 - Board thickness mean deviation per treatment, thickness standard deviation and relative deviation, in percentage

\begin{tabular}{cccc}
\hline Tratamentos & $\begin{array}{c}\text { Desvio } \\
(\mathrm{mm})^{*}\end{array}$ & $\begin{array}{c}\text { Desvio } \\
\text { Padrão }(\mathrm{mm})\end{array}$ & $\begin{array}{c}\text { Desvio } \\
\text { relativo \% }\end{array}$ \\
\hline 1 & $+0,57 \mathrm{~A}^{1}$ & 1,00 & $3,01 \mathrm{~B}$ \\
2 & $-0,09 \mathrm{C}$ & 1,15 & $2,75 \mathrm{~B}$ \\
3 & $+0,11 \mathrm{~B}$ & 1,13 & $2,74 \mathrm{~B}$ \\
4 & $-0,61 \mathrm{E}$ & 0,95 & $2,86 \mathrm{~B}$ \\
5 & $-0,36 \mathrm{D}$ & 1,13 & $2,75 \mathrm{~B}$ \\
6 & $-0,88 \mathrm{~F}$ & 1,18 & $3,90 \mathrm{~A}$ \\
\hline
\end{tabular}

Em que (+): acima da espessura meta e (-): abaixo da espessura meta de $31,5 \mathrm{~mm}$; e DP: desvio-padrão $(\mathrm{mm}) .{ }^{1}$ Ao longo das colunas, médias seguidas pela mesma letra não diferem entre a $95 \%$ de probabilidade, pelo teste de Tukey.

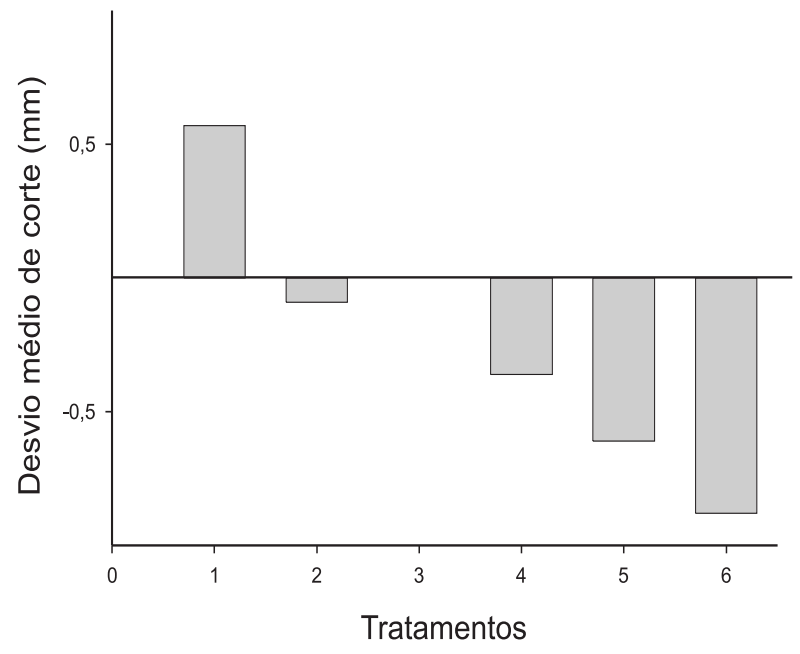

Figura 2 - Desvio médio na espessura das tábuas, em mm, por tratamento.

Figure 2-Mean thickness deviation of the boards, in mm, per treatment.

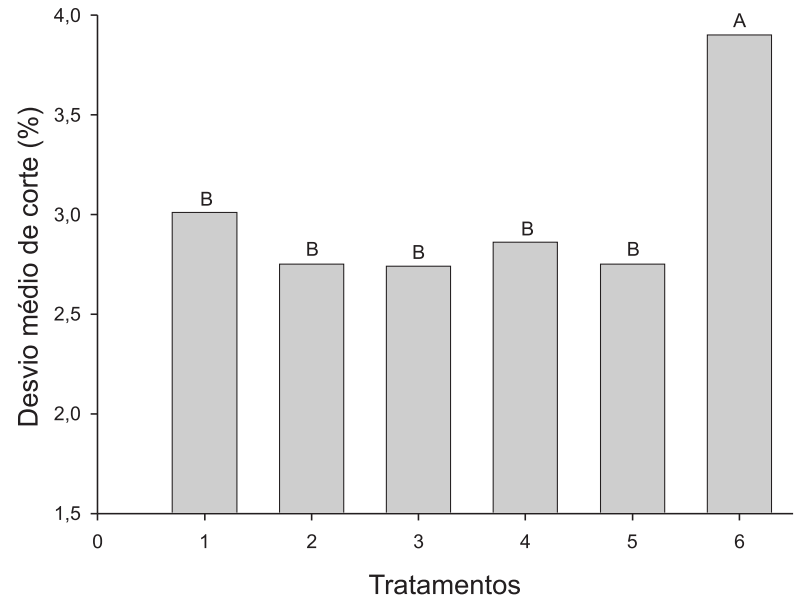

Figura 3-Desvio médio relativo, em porcentagem, na espessura das tábuas, por tratamento.

Figure 3 - Board relative percentage thickness deviation by treatment.

Os desvios na espessura das tábuas acima dos valores propostos para a espessura desejada ocorreram nos tratamentos $1(+0,57)$ e $3(+0,11)$, sendo o desvio observado no tratamento 1 cerca de cinco vezes maior do que o desvio verificado no tratamento 3. Portanto, quando o desdobro foi realizado com lâminas de serra com passo único e ângulo de ataque de $27^{\circ}$, as tábuas apresentaram desvios acima da espessura-meta de corte. 
Os demais tratamentos apresentaram o desvio de corte abaixo da espessura-meta. O maior desvio de corte $(\mathrm{mm})$ negativo ocorreu quando foram utilizados o passo variado e o ângulo de ataque de $26^{\circ}$.

O efeito do perfil e o passo dos dentes por classe de diâmetro nos desvios da espessura-meta por tratamento é mostrado no Quadro 3 e nas Figuras 4 e 5 . Na menor classe de diâmetro, observou-se que não houve diferença significativa entre os tratamentos 2 e 4 (ângulo de ataque igual a $26^{\circ}$ com diferentes alturas do dente) na menor classe de diâmetro. Observou-se ainda que, quando se utilizou um ângulo de ataque de $26^{\circ}$ ou $27^{\circ}$ e espaçamento variado entre as pontas dos dentes (tratamentos 4 e 5), também não houve diferença significativa entre eles. Os demais tratamentos $(1,3,5$ e 6$)$ diferiram significativamente entre si. O maior desvio acima da espessura desejada ocorreu na madeira desdobrada com dentes com passo de $57,15 \mathrm{~mm}$, altura de $22 \mathrm{~mm}$ e ângulo de ataque igual a $27^{\circ}$ (tratamento 1). Enquanto o maior desvio negativo ocorreu quando se empregaram dentes com passo variado, altura igual a $22 \mathrm{~mm}$ e ângulo de ataque igual a $26^{\circ}$ (tratamento 6).

Para a maior classe diamétrica, os desvios de corte produzidos quando se empregaram os tratamentos 4 e 6 foram significativamente iguais entre si, abaixo da espessura-meta de $31,5 \mathrm{~mm}$ e diferentes dos demais tratamentos. Comparando o efeito das classes diamétricas dentro de cada tratamento, observou-se que os desvios de corte dos tratamentos 1 e 6 não foram afetados pelo diâmetro das toras. Nos demais tratamentos, o efeito da classe de diâmetro foi significativo. Isso está de acordo com Senai (s.d.), que afirmou que a variação na espessura da madeira serrada, encontrada na maioria das serrarias da região amazônica, está correlacionada com as alturas de corte, com deficientes avanços por dente. Neste experimento, observou-se que a menor variação em torno da espessura-meta de corte foi encontrada na classe diamétrica 2 e no tratamento 3 . O maior desvio de corte ocorreu na classe de menor diâmetro e tratamento 6 . A Figura 4 permite melhor visualização dos dados apresentados no Quadro 3.

Relacionando os valores dos desvios na espessura com a capacidade da garganta em armazenar cavaco, observou-se que nas condições propostas pela pesquisa a maior capacidade da garganta, tratamentos 3 e 4, correspondeu, respectivamente, ao menor e ao terceiro menor desvio de corte.
Quadro 3 - Desvios médios na espessura das tábuas absolutos e relativos por tratamento e classe diamétrica Table 3-Absolute and relative mean board thickness deviations per treatment and diameter class

\begin{tabular}{ccccr}
\hline Tratamentos & \multicolumn{2}{c}{ Desvio $(\mathrm{mm})$} & \multicolumn{2}{c}{ Desvio relativo $(\%)$} \\
\cline { 2 - 5 } & $1^{*}$ & 2 & 1 & 2 \\
\hline 1 & $+0,50 \mathrm{Aa}^{1}$ & $+0,65 \mathrm{Aa}$ & $2,50 \mathrm{Bc}$ & $3,52 \mathrm{Ab}$ \\
2 & $-0,42 \mathrm{Ad}$ & $+0,23 \mathrm{Bb}$ & $2,64 \mathrm{Ac}$ & $2,88 \mathrm{Acd}$ \\
3 & $+0,26 \mathrm{Ab}$ & $-0,03 \mathrm{Bc}$ & $2,84 \mathrm{Abc}$ & $2,65 \mathrm{Ad}$ \\
4 & $-0,29 \mathrm{Bcd}$ & $-0,94 \mathrm{Ae}$ & $2,44 \mathrm{Bc}$ & $3,28 \mathrm{Abc}$ \\
5 & $-0,14 \mathrm{Bc}$ & $-0,60 \mathrm{Ad}$ & $3,02 \mathrm{Ab}$ & $2,50 \mathrm{Bd}$ \\
6 & $-0,96 \mathrm{Ae}$ & $-0,82 \mathrm{Ae}$ & $3,71 \mathrm{Aa}$ & $4,11 \mathrm{Aa}$ \\
\hline
\end{tabular}

${ }^{*}$ Em que 1: diâmetros das toras compreendido entre 24 e $34 \mathrm{~cm}$; 2: diâmetros entre 35 e $47 \mathrm{~cm}$; (+): acima da espessura meta; e (-): abaixo da espessura-meta de $31,5 \mathrm{~mm}$.

${ }^{1}$ Ao longo da mesma linha, médias seguidas da mesma letra maiúscula ou ao longo da mesma coluna e pela mesma letra minúscula não diferem entre si, a $95 \%$ de probabilidade, pelo teste de Tukey.

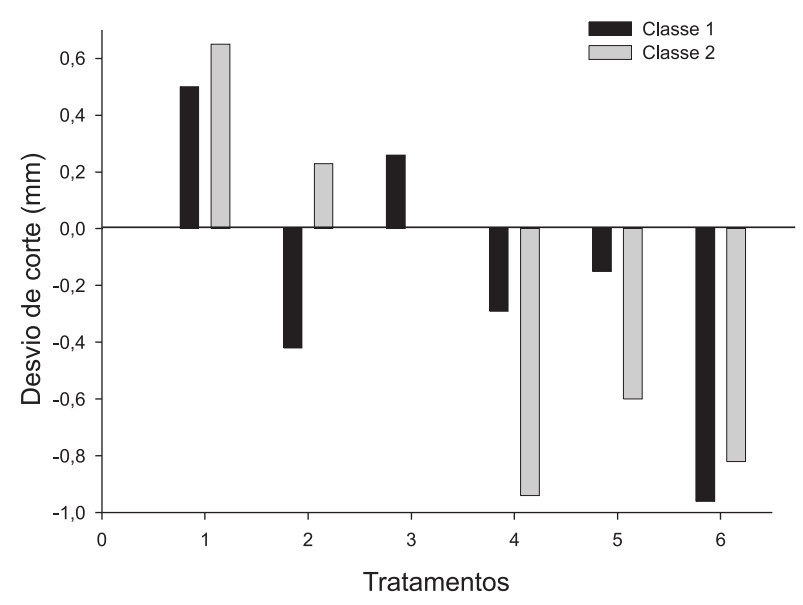

Figura 4-Desvio médio na espessura das tábuas por tratamento e classe diamétrica.

Figure 4-Mean board thickness deviation by treatment and log diameter classes.

Desvios acima da espessura-meta de corte ocorreram nas duas classes diamétricas no tratamento 1 . Os tratamentos 4, 5 e 6 apresentaram desvios abaixo da espessura-meta de corte tanto na classe de diâmetro 1 quanto na classe 2 . Assim, considerando a menor classe de diâmetro no tratamento 1 , a cada 100 cortes realizados pelas lâminas de serra com tal geometria de dente será produzido um volume de resíduo, correspondente ao de duas tábuas, sendo uma de 30 $\mathrm{mm}$ de espessura e outra de $20 \mathrm{~mm}$. Se considerarmos a classe diamétrica 2, a cada 100 cortes efetuados gera-se como resíduo o volume correspondente a duas tábuas de $32,5 \mathrm{~mm}$. Considerando os desvios negativos, ressalta-se que o rendimento da serraria

R. Árvore, Viçosa-MG, v.32, n.5, p.939-947, 2008 
diminui em função da adequação da espessura da tábua a uma espessura menor do que a desejada de corte. Portanto, não houve relação entre a menor classe diamétrica com o menor desvio de corte, conforme mencionado pela literatura. Comparando o efeito de cada tratamento entre as classes de diâmetro, observaram-se diferenças significativas entre classes de diâmetro nos tratamentos $2,3,4$ e 5 . verificou-se que desvios significativamente menores ocorreram com os tratamentos 2 e 3 na classe de maior diâmetro. $\mathrm{O}$ menor desvio foi observado na classe das toras de menor diâmetro, e metade dos tratamentos $(3,4$ e 5) apresentou menor desvio de corte. Nos demais tratamentos, a maior classe de diâmetro foi que apresentou o menor desvio de corte, em torno da espessura desejada. Uma melhor visualização dos desvios de corte em função das classes diamétricas e dos tratamentos pode ser obtida, observando-se as Figuras 4 e 5. Também, não houve ganho de qualidade da madeira serrada de eucalipto, quando se trabalhou com passo variado, conforme sugerido por Sandvik (1999) e Armstrong (2005).

O maior desvio de corte em valores absolutos, em porcentagem, ocorreu no tratamento 6 , em que se utilizou passo variado, com ângulo de ataque de $26^{\circ}$ nas duas classes de diâmetro. O menor desvio foi encontrado na classe de menor diâmetro e no tratamento 4. Considerando, ainda, o desvio absoluto em porcentagem, observou-se que os tratamentos 1, 2, 3 e 4 e a classe de menor diâmetro apresentaram também menor desvio em porcentagem. Contudo, na maior classe diamétrica os menores desvios foram observados nos tratamentos 1,3 e 5 .

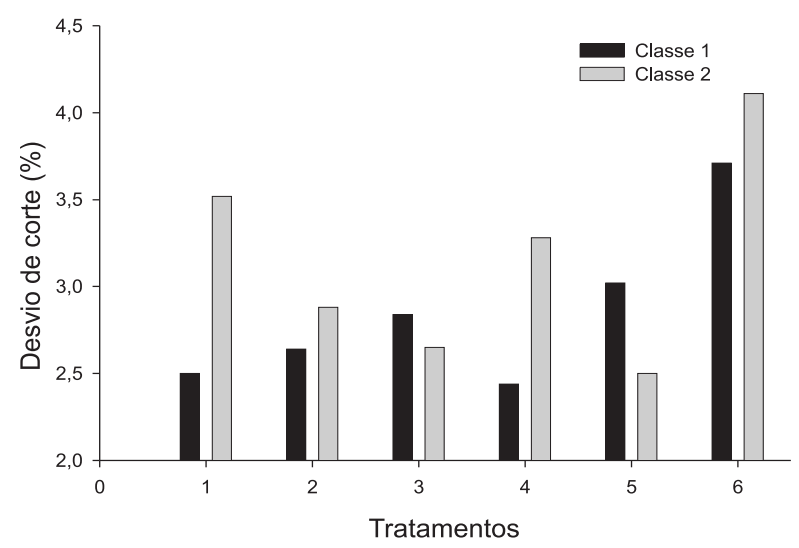

Figura 5-Desvio médio na espessura das tábuas em porcentagem dos valores relativos por tratamento e classe de diâmetro.

Figure 5 - Relative percentage of board thickness deviation by treatment and diameter classes.

R. Árvore, Viçosa-MG, v.32, n.5, p.939-947, 2008
O Quadro 4 e Figura 6 apresentam os desvios médios de corte por ponto de medição e tratamento. Nos pontos de medição 2 e 3, obtiveram-se resultados iguais em todos os tratamentos. Observou-se ainda que, nos tratamentos 4 e 5, não houve desvio significativo nos pontos de medição 1 e 4 e 1 e 5 , respectivamente. No tratamento 1 , nas medições realizadas nas duas extremidades observaram-se desvios numericamente inferiores aos demais, e no ponto de medição 5 o desvio foi negativo, portanto inferior à espessura-meta. Já nos tratamentos 5 e 6 , nos pontos de medição 1 e 5 , obtiveram-se desvios numericamente maiores e, portanto, mais distantes da espessura-meta de corte. Em todos os tratamentos, exceto no ponto de medição 1 do tratamento 1 , a espessura de corte nas extremidades das tábuas foi inferior àquela desejada. Portanto, ocorreu desvio no fio de corte tanto na região de inserção da lâmina de serra quanto na extremidade oposta.

A Figura 6 facilita a observação desses desvios médios de corte por tratamento e ponto de medição e indica uma mesma tendência em todos os tratamentos. Partindo da extremidade na qual ocorreu o início do desdobro (ponto de medição 1), observou-se que a espessura das tábuas aumentou independentemente de ter desvios positivos ou negativos até o ponto de medição 3, decrescendo posteriormente conforme o corte teve prosseguimento. Portanto, todas as tábuas tiveram formato ligeiramente convexo.

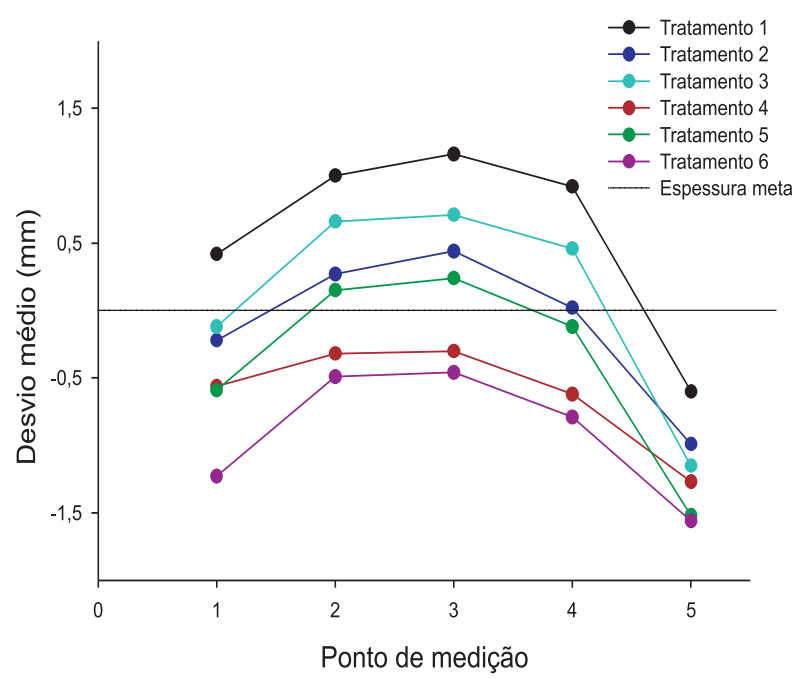

Figura 6-Desvio médio na espessura das tábuas por tratamento e ponto de medição.

Figure 6-Mean board thickness deviation by treatments and measurement point. 
Quadro 4 - Desvio médio* na espessura das tábuas por tratamento e ponto de medição (mm) Table 4-Mean board thickness deviation per treatment and measurement point ( $\mathrm{mm}$ )

\begin{tabular}{ccccccc}
\hline Ponto de medição & \multicolumn{5}{c}{ Tratamentos } \\
\cline { 2 - 7 } & 1 & 2 & 3 & 4 & 5 & 6 \\
\hline 1 & $+0,42 \mathrm{Ab}^{1}$ & $-0,22 \mathrm{Bc}$ & $-0,12 \mathrm{Bc}$ & $-0,56 \mathrm{Cb}$ & $-0,59 \mathrm{Cc}$ & $-1,23 \mathrm{Dc}$ \\
2 & $+1,00 \mathrm{Aa}$ & $+0,27 \mathrm{Ca}$ & $+0,66 \mathrm{Ba}$ & $-0,32 \mathrm{Da}$ & $+0,15 \mathrm{Ca}$ & $-0,49 \mathrm{Da}$ \\
3 & $+1,16 \mathrm{Aa}$ & $+0,44 \mathrm{Ca}$ & $+0,71 \mathrm{Ba}$ & $-0,30 \mathrm{Ea}$ & $+0,24 \mathrm{Da}$ & $-0,46 \mathrm{Ea}$ \\
4 & $+0,92 \mathrm{Ac}$ & $+0,02 \mathrm{Cb}$ & $+0,46 \mathrm{Bb}$ & $-0,62 \mathrm{~Eb}$ & $-0,12 \mathrm{Db}$ & $-0,79 \mathrm{~Eb}$ \\
5 & $-0,60 \mathrm{Ad}$ & $-0,99 \mathrm{Bd}$ & $-1,15 \mathrm{Cd}$ & $-1,27 \mathrm{Cc}$ & $-1,52 \mathrm{Ec}$ & $-1,56 \mathrm{DEd}$ \\
\hline
\end{tabular}

${ }^{*}$ Em que (+): acima da espessura-meta e (-): abaixo da espessura-meta de 31,5 mm.

${ }^{1}$ Ao longo da mesma linha, médias seguidas da mesma letra maiúscula ou ao longo da mesma coluna e pela mesma letra minúscula não diferem entre si, a $95 \%$ de probabilidade, pelo teste de Tukey.

Os valores dos desvios médios de corte em percentagem dos valores relativos por tratamento e ponto de medição podem ser observados no Quadro 5. Observou-se que os maiores desvios, em todos os tratamentos, ocorreram na região de inserção (ponto de medição 1) ou de saída da lâmina de serra (ponto de medição 5). O maior desvio foi notado no ponto de medição 5 e no tratamento 6 .

No Quadro 6 e na Figura 7 estão apresentados os desvios médios de corte por tratamento e tábuas. A lâmina de serra dotada de dentes com perfil correspondente ao tratamento 1 produziu todas as tábuas com espessura superior ao valor desejado. Entretanto, lâminas dotadas de dentes com perfis correspondentes aos tratamentos 4 e 6 resultaram em tábuas com espessuras abaixo daquela desejada. Exceto no tratamento 1, observou-se, de modo geral, aumento na espessura da peça serrada até a quinta tábua. A sexta tábua sempre foi retirada com espessura significativamente menor que a quinta tábua. Portanto, foram observadas diferenças significativas nos desvios médios de corte por tratamento e tábua em relação à posição da tábua na tora desdobrada. A Figura 6 permite melhor visualização dos desvios médios ocorridos nas tábuas em razão dos diversos perfis de dentes.

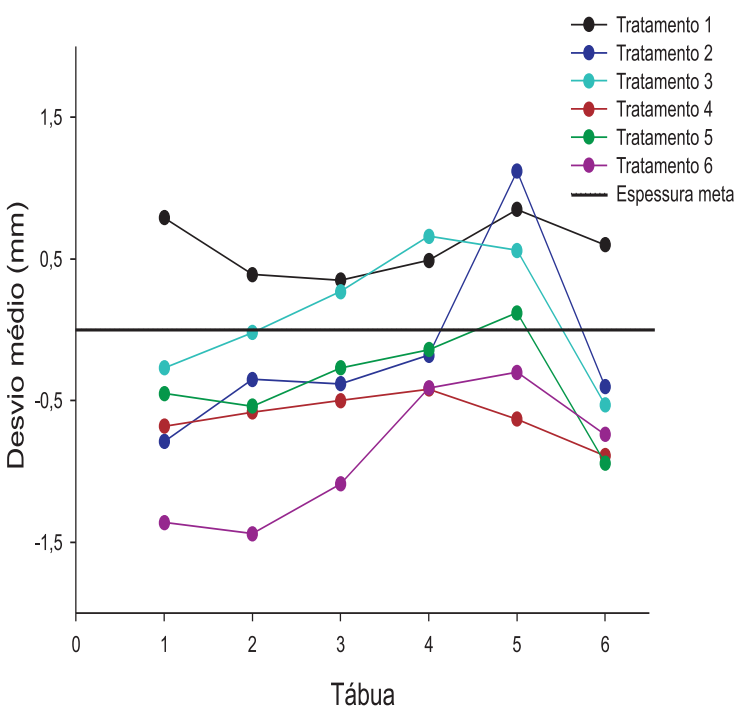

Figura 7 - Desvio médio na espessura por tratamento e tábua. Figure 7 - Mean thickness deviation by treatment and board.

Quadro 5 - Desvio na espessura das tábuas em porcentagem dos valores relativos por tratamento e ponto de medição Table 5-Relative percentage of board thickness deviation as affected by treatment and measurement point.

\begin{tabular}{|c|c|c|c|c|c|c|}
\hline \multirow[t]{2}{*}{ Ponto de medição } & \multicolumn{6}{|c|}{ Tratamentos } \\
\hline & 1 & 2 & 3 & 4 & 5 & 6 \\
\hline 1 & $1,83 \mathrm{Bd}^{1}$ & $1,78 \mathrm{Cd}$ & $1,7 \mathrm{Cc}$ & $2,32 \mathrm{Bc}$ & $2,33 \mathrm{Bb}$ & $4,15 \mathrm{Ab}$ \\
\hline 2 & $3,31 \mathrm{Ab}$ & $2,37 \mathrm{BCc}$ & $2,72 \mathrm{Bb}$ & $2,45 \mathrm{Bb}$ & $1,94 \mathrm{Cb}$ & $2,62 \mathrm{Bc}$ \\
\hline 3 & $3,78 \mathrm{Aa}$ & $2,93 \mathrm{Bb}$ & $2,78 \mathrm{BCb}$ & $2,78 \mathrm{BCb}$ & $2,4 \mathrm{Cb}$ & $3,19 \mathrm{Bb}$ \\
\hline 4 & $3,4 \mathrm{Ba}$ & $2,87 \mathrm{Cb}$ & $2,48 \mathrm{CDb}$ & $2,48 \mathrm{CDb}$ & $2,1 \mathrm{Db}$ & $4,06 \mathrm{Ab}$ \\
\hline 5 & $2,73 \mathrm{Dc}$ & $3,36 \mathrm{Ca}$ & $4,02 \mathrm{Ca}$ & $4,27 \mathrm{Ca}$ & $5,02 \mathrm{Ba}$ & $5,52 \mathrm{Aa}$ \\
\hline
\end{tabular}

${ }^{1}$ Ao longo da mesma linha, médias seguidas da mesma letra maiúscula ou ao longo da mesma coluna e pela mesma minúscula não diferem entre si, a $95 \%$ de probabilidade, pelo teste de Tukey. 
Quadro 6 - Desvio médio na espessura das tábuas, corte por tratamento e tábua Table 6-Mean board thickness deviation, cut by treatment and board.

\begin{tabular}{|c|c|c|c|c|c|c|}
\hline \multirow[t]{2}{*}{ Tábua } & \multicolumn{6}{|c|}{ Tratamentos } \\
\hline & 1 & 2 & 3 & 4 & 5 & 6 \\
\hline 1 & $+0,79 \mathrm{Aa}$ & $-0,79 \mathrm{Bc}$ & $-0,27 \mathrm{Bd}$ & $-0,68 \mathrm{Cb}$ & $-0,45 \mathrm{Bc}$ & $-1,36 \mathrm{Dd}$ \\
\hline 2 & $+0,39 \mathrm{Ac}$ & $-0,35 \mathrm{Cc}$ & $-0,02 \mathrm{Bc}$ & - 0,56 Dab & - 0,54 CDc & $-1,44 \mathrm{Ed}$ \\
\hline 3 & $+0,35 \mathrm{Ac}$ & $-0,38 \mathrm{Bc}$ & $+0,27 \mathrm{Ab}$ & $-0,50 \mathrm{Ca}$ & $-0,27 \mathrm{Bbc}$ & - 1,09 Dc \\
\hline 4 & $+0,49 \mathrm{Abc}$ & $-0,18 \mathrm{Bb}$ & $+0,66$ Аa & - 0,42 Ca & $-0,14 \mathrm{Bb}$ & $-0,41 \mathrm{Ca}$ \\
\hline 5 & $+0,85 \mathrm{Ba}$ & $+1,12 \mathrm{Aa}$ & $+0,56 \mathrm{Ca}$ & $-0,63 \mathrm{Fb}$ & $+0,12 \mathrm{Da}$ & - 0,30 Ea \\
\hline 6 & $+0,60 \mathrm{Ab}$ & $-0,40 \mathrm{Bc}$ & $-0,53 \mathrm{Be}$ & - 0,89 CDc & $-0,94 \mathrm{Dd}$ & $-0,74 \mathrm{Cb}$ \\
\hline
\end{tabular}

Em que (+): acima da espessura-meta e (-): abaixo da espessura-meta de $31,5 \mathrm{~mm}$.

Ao longo da mesma linha, médias seguidas da mesma letra maiúscula ou ao longo da mesma coluna e pela mesma letra minúscula não diferem entre si, a $95 \%$ de probabilidade, pelo teste de Tukey.

\section{CONCLUSÕES}

Lâminas de serra com ângulo de ataque de $27^{\circ}$ e passo único tanto com altura do dente de $22 \mathrm{~mm}$ quanto com 25,4 mm geraram desvios acima da espessura-meta. A menor variação em torno da espessura-meta foi obtida quando se utilizaram lâminas de serra de ângulo de ataque de $27^{\circ}$ e com altura do dente de 25,4 mm; o maior desvio de corte ocorreu quando o desdobro foi efetuado com passo variado e ângulo de ataque de $26^{\circ}$. A menor variação em relação à espessura-meta ocorreu no tratamento 3, na classe diamétrica 2 .

A utilização de passo variado, de modo geral, foi o que ocasionou maiores desvios de corte. Os pontos localizados nas extremidades das tábuas, de todos os tratamentos, apresentaram espessura de corte inferior à dos demais. Não se observou uma tendência para o desvio de corte.

\section{AGRADECIMENTOS}

À serraria da Aracruz Produtos de Madeira LTDA. (APM), nas pessoas dos engenheiros Vicente Lelis, Frederico Soares e Manoel Tadeu, e ao CNPq, pela bolsa concedida.

\section{REFERÊNCIAS}

ALVES, E. C. S. C.; XAVIER, A.; OTONI, W. C. Organogênese in vitro a partir de explante caulinar na regeneração de clones de Eucalyptus grandis W. Hill ex Maiden x Eucalyptus. urophylla S. T. Blake. Revista Árvore, v.28, n.5, p.643-653, 2004.

R. Árvore, Viçosa-MG, v.32, n.5, p.939-947, 2008
ARMSTRONG. Variable pitch tooth and gullet depths. 2005. Disponível em: $<$ http// www.armstrongblue.com/publications $>$ Acesso em: 06 de out. 2006.

BROWN, T. (Ed) Quality control in lumber manufacturing. San Francisco: Miller Freeman, 1982. 288p.

CARMO, J. F. Influencia da geometria dos dentes das lâminas de serra-fita na qualidade e produtividade da madeira serrada. 2004. n. FOLHAS. Dissertação (Mestrado em Ciências Ambientais e Florestais) - Universidade Federal Rural do Rio de Janeiro, Seropédica, 2004.

ELEOTÉRIO, J. R.; LINDOLFO, S.; SIDINEI, J. L. Caracterização de peças de madeira produzidas em serraria visando o controle de qualidade. Ciência Florestal, v.6, n.1, p.89-99, 1996.

LUNSTRUM, S. J. Circular sawmills and their efficient operation. Atlanta: U.S. Department of Agriculture Forest Service, 1993. 86p.

NERI, A. C.; GONSALVES, R.; HERNADEZ, R. E. Forças de corte ortogonal 90-90 em três espécies de madeira de eucalipto. Revista Brasileira de Engenharia Agrícola e Ambiental. v.4, n.2, p.275-280,2000. 
PIPINO, N. O. Madeira serrada pode ter melhor aproveitamento. Revista da Madeira, v.60, n.1, p.54-56, 2001.

SANDVIK. The Handbook: production, use and maintenance of wood bandsaw blades. Sweden: Sansvik Steel, 1999.

STEELE, P. H.; ARAMAN, P. A.; BODEN, C. Economic choise for hardwood sawmill operations. Starkville: Forest and Wildlife Research Center, Mississipe State University, [199-]. 22p. (Research Bulletin, FP 252).

UDDEHOLM. How to increase profit in bandsawing. Munkfors:Uddeholm Strip, [199-] 44p.
SILVA, J. R. M. Relações da usinabilidade e aderência do verniz com as propriedades fundamentais do Eucalyptus grandis, Hill Ex. Maiden. 2002. 204f. Tese (Doutorado emEngenharia Florestal) Universidade Federal do Paraná, Curitiba, 2002.

SILVA, J. R. M. et al. Influência da morfologia das fibras na usinabilidade da madeira de Eucalyptus grandis Hill ex. Maiden. Revista Árvore, v.29, n.3, p. 479-487, 2005.

SERVIÇO DE NACIONALDEAPRENDIZAGEM INDUSTRIAL - SENAI. Sinop - MT. Parâmetros de corte, 15 p. [200-]

WILlistON, E. M. How to increase profit in bandsawing: practical models for increased lumber recovery. Sweden: Uddeholm, 1976. 44p. 
